\title{
O controle dos processos logísticos, uma condição prévia para uma política do global sourcing: o caso da indústria automobilística e do varejista mundial
}

\begin{abstract}
Resumo
As empresas estão, atualmente, expostas a uma competição mundial que se intensifica pelos gigantescos movimentos de concentração realizados nos últimos quinze anos em todos os setores de atividade e pelo aparecimento de concorrentes oriundos dos novos países industrializados (China, Índia, Brasil, Europa Oriental, etc.). Grandes empresas ocidentais têm identificado rapidamente a oportunidade que representa o recurso a fornecedores oriundos destes novos países (o global sourcing).

Nesta comunicação, analisamos as exigências e os desempenhos em termos de custo, de qualidade, de estabilidade, de reatividade e de flexibilidade dos processos logísticos ligados às compras mundiais em setores particularmente engajados na globalização: a indústria automobilística e o varejista mundial. Em seguida, nós proporemos uma generalização.
\end{abstract}

Palavras-chave

Logística, abastecimento global.

\section{Control of logistic processes as prerequisite to a policy of global sourcing: the cases of the automotive industry and the worldwide retailer}

\begin{abstract}
Enterprises are nowadays exposed to a worldwide competition intensified by huge concentration movements ocurred in the last fifteen years in all economic sectors, as well by the appearance of competitors from new industrialized countries (China, India, Brazil, Eastern Europe, etc.). Large western companies have fastly identified opportunities that arise from suppliers installed in these new countries (global sourcing).

In this paper we analyse requirements and performance regarding cost, quality, stability, responsiveness and flexibility of logistic processes associated to international procurement in industries specially engaged in globalization : the automotive industry and the global retailer. After that, we propose a generalization.
\end{abstract}

Key words

Logistics, global sourcing. 


\section{INTRODUC̣̃̃O}

As empresas dos "velhos" países industrializados estão, atualmente, expostas a uma competição mundial que se intensifica com os gigantescos movimentos de concentração realizados, nos últimos quinze anos, em todos os setores de atividade, e pelo aparecimento de concorrentes oriundos dos novos países industrializados (China, Índia, Brasil, Europa Oriental, etc.). Estes países conhecem, ao mesmo tempo, taxas de crescimento elevadas, com um mercado interno em crescimento, e custos baixos de mão-de-obra.

Entretanto, como esta competição ocorre principalmente sobre os preços, as grandes empresas ocidentais têm identificado rapidamente a oportunidade que representa o recurso a fornecedores oriundos destes novos países (o global sourcing) para reduzir seus custos de compras, beneficiando-se de uma mão-de-obra barata, mas também ao mesmo tempo para pressionar os fornecedores tradicionais, obrigando-os a reduzir seus preços e/ou a transferir sua produção para países com menor custo. O sucesso do global sourcing supõe, contudo, que sejam reunidas simultaneamente quatro condições:

- o nível dos custos de mão-de-obra dos novos fornecedores "mundiais" deve ser significativamente mais baixo que o dos fornecedores tradicionais locais, para compensar todos os sobrecustos e os riscos ligados às compras mundiais;

- o nível tecnológico e as capacidades de inovação atingidas pelos novos fornecedores devem ser comparáveis aos dos fornecedores tradicionais;

- os novos fornecedores devem se empenhar em respeitar as regras que destacam princípios de desenvolvimento durável aos planos econômico (rentabilidade e modos de governança das empresas), social (salários e condições de trabalho satisfatórios) e ambiental (responsabilidade ecológica). Efetivamente, tendo em conta a crescente sensibilidade dos consumidores dos países industrializados quanto aos princípios do desenvolvimento durável, as empresas que apelam aos fornecedores não respeitando estes princípios arriscam-se a ser confrontadas com o desinteresse dos seus clientes, ou mesmo um boicote dos seus produtos;

- os complexos processos logísticos que ligam uma empresa cliente a seus fornecedores mundiais devem estar estabilizados, sejam quais forem os riscos e os múltiplos desafios com os quais eles são confrontados.

Neste texto, analisamos as exigências e os desempenhos em termos de custo, qualidade, estabilidade, confiabilidade, reatividade e flexibilidade dos processos logísticos ligados às compras mundiais. Ora, estes critérios devem ser ri- gorosamente respeitados, apesar das múltiplas defasagens de ordem geográfica (das longas distâncias entre fornecedores e clientes), comercial (práticas comerciais diferentes ligadas às culturas específicas), jurídica (complexidade dos contratos internacionais entre países de sistemas jurídicos heterogêneos), organizacional (modos de governança das empresas) e tecnológica, que podemos observar entre as firmas envolvidas nas trocas globalizadas.

Após expor as principais razões que levam as empresas a globalizar suas compras, sublinharemos dois setores particularmente engajados na globalização: a indústria Automobilística e o varejista mundial. Em seguida, proporemos uma generalização.

\section{AS RAZÕES DO DESENVOLVIMENTO DA POLÍTICA DE COMPRAS EM ESCALA MUNDIAL}

\section{Uma forte competição sobre os preços e, portanto, sobre os custos}

Face a uma concorrência que se amplifica, as grandes empresas de hoje em dia apelam massivamente aos fornecedores de baixo custo, apesar dos riscos que correm. As diferenças de custo de mão-de-obra entre os países são de fato muito relevantes: em 2001 o custo/hora da mãode-obra havia se estabelecido em 20 dólares nos Estados Unidos, em 16 dólares na França, em 3 dólares no Brasil e em 0,4 dólares na China ${ }^{(1)}$.

Um estudo recente do grupo Accenture ${ }^{(2)}$, realizado a partir de entrevistas com responsáveis de compras de 238 grandes grupos industriais europeus e americanos, mostra que estes têm a intenção de quase dobrar suas compras junto aos países de baixo custo de mão-de-obra. Tais compras passarão de 70,2 bilhões de dólares em 2004 a 127 bilhões de dólares em 2007. Submetidas a intensas pressões concorrenciais, as empresas voltam-se em direção dos fornecedores de baixo custo (20\% de redução dos custos em compras entre 2004 e 2007) para conseguir baixar seus preços sem reduzir suas margens de lucro, às vezes conseguindo até mesmo aumentá-lo.

Esta modificação geográfica dos fluxos de compras, que verá parte das compras dos países de origem dos fornecedores passar de 45\% em 2004 para 36\% em 2007, traduz-se por riscos de fechamento de usinas e de perda de empregos para os fornecedores dos "velhos países". Estes reagem, baixando seus preços, relocalizando freqüentemente suas usinas, mas também desenvolvendo políticas ativas de inovação (sobre novos produtos e/ou sobre novas condutas) para manter suas fatias de mercado e suas atividades dentro dos países do Norte.

\section{A busca de economia de escala}

$\mathrm{O}$ recurso aos fornecedores dos países emergentes per- 
mite, também, aproximar-se das fontes de matérias-primas e, portanto, assegurar e intensificar seus abastecimentos.

Criando capacidades nestes países emergentes, os industriais dos países do Norte que transferem sua produção para países com menor custo podem também obter importantes economias de escala quando eles produzem os produtos que exportam aos mercados locais em pleno crescimento: é o caso da indústria automobilística (montadoras e fornecedores de autopeças) e dos produtores de bens de consumo na indústria têxtil, eletrônica, de brinquedos, de móveis, etc.

Aliás, com bastante freqüência, sejam quais forem as regras estabelecidas pela OMC, o acesso a estes novos mercados promissores, se comparados com os mercados domésticos saturados, está "de fato" ligado à obrigação de aí desenvolver as atividades de produção. O mesmo se passa em relação aos hipermercados, que somente podem abrir novos pontos-de-venda nos países emergentes desde que obedeçam à condição de os abastecer a partir dos fornecedores locais, que exportam também em direção às suas redes de lojas na Europa ou nos Estados Unidos.

\section{0 recurso aos países dotados de redes de infra-estrutura potentes}

Um dos maiores riscos que encontramos em abastecer-se junto aos fornecedores oriundos dos países emergentes, mesmo competentes e com um bom desempenho, é enfrentar uma ruptura brutal na cadeia logística ${ }^{(3)}$ de exportação.

Freqüentemente, tais falhas estão ligadas às fragilidades das redes de infra-estrutura disponíveis em muitos países emergentes, que se revelam incapazes de absorver o aumento massivo de tráfico induzido por um crescimento exponencial das compras. Três tipos de redes são particularmente vulneráveis nos novos países industrializados:

- redes de infra-estrutura de transporte (para o escoamento das mercadorias);

- redes de infra-estrutura da informação (para a transferência dos dados); e

- redes de infra-estrutura de formação especializada (para dispor de competências técnicas necessárias em transporte e logística).

Os investimentos realizados pelos Estados nas infraestruturas de transporte (rodovias e auto-estradas, vias ferroviárias, vias fluviais, portos marítimos e fluviais, terminais multimodais e plataformas logísticas públicas) são freqüentemente insuficientes para suprir o volume de tráfego, que pode crescer de 5 a $20 \%$ por ano. A conseqüência disso é o engarrafamento das infra-estruturas portuárias de exportação, a incerteza dos prazos de encaminhamento interno etc., que desorganiza completamente os canais logísticos de exportação.
No Brasil, os investimentos aplicados em infra-estrutura de transporte não ultrapassam $0,2 \%$ do PIB, valor que não permite nem mesmo manter as redes existentes ${ }^{(4)}$. Ao contrário, em 2003, a China, segundo a mesma fonte, destinou $10 \%$ de seu PIB (aumentando o mesmo mais de $11 \%$ por ano), o que constitui um fator de atração decisiva para as empresas que desejam se abastecer nesse país.

Um outro ponto fraco dos países emergentes reside na grande insuficiência das redes de formação especializadas nas áreas da logística e dos transportes, ainda que indispensáveis para colocar em prática as Supply Chains ${ }^{(3)}$ e a qualidade das múltiplas operações de exportação. Paradoxalmente, esta insuficiência de competências logísticas é mais sensível nos níveis hierárquicos inferiores e intermediários que no nível superior. Muitos países emergentes têm Universidades que oferecem mestrados em Transporte e em Logística, mas as formações técnicas são complemente negligenciadas. Em oposição, se nos referimos ao que se passa nos países do Norte, para um diploma de Mestrado em Logística ou em Transporte, são emitidos dez vezes mais diplomas de técnicos dentro dos mesmos domínios de competência... Parece-nos, no entanto, que o desenvolvimento de redes de transferência de dados acompanha sem maiores dificuldades o acentuado crescimento das trocas de informação pelo EDI (Intercâmbio Eletrônico de Dados) que se estabelecem entre atores das Supply Chains internacionais.

\section{O CASO DA INDÚSTRIA AUTOMOBILÍSTICA}

A indústria automobilística apresenta a característica de ser atualmente globalizada, tanto do lado das montadoras (as oito primeiras montadoras representam mais de três quartos dos veículos montados), quanto dos fornecedores de autopeças, implantados nos quatro principais mercados: a Ásia, a Europa a América do Norte e a América do Sul.

\section{Uma negociação difícil com os fornecedores de autopeças para construir uma Supply Chain ampla}

A principal dificuldade que encontram as montadoras que solicitam aos fornecedores de autopeças oriundos dos países emergentes para abastecer de peças suas plantas nos seus respectivos países de origem é tornar os fluxos compatíveis com a política de abastecimento just in time (o lean production, implicando o just in time para as entregas) que foi adotada.

É evidente que a distância geográfica dos fornecedores, as múltiplas disparidades culturais e organizacionais entre os clientes e fornecedores e as incertezas que ameaçam as cadeias logísticas internacionais de abastecimento exigem construir as Supply Chains fundadas em princípios distintos daqueles impostos nos países industrializados. 
Por exemplo, em 2004, a montadora PSA (Peugeot e Citroën), para a qual as compras representam $75 \%$ do preço de fabricação, abasteceu-se em 95\% de seus fluxos de peças na Europa do Oeste. Seu projeto Global Sourcing irá conduzir em 2010 a $75 \%$, ou pelo menos, $55 \%$ do volume de suas compras na Europa do Oeste, recorrendo massivamente aos fornecedores localizados no resto do mundo, ou seja, na Ásia, na Europa do Leste e talvez na América do Sul.

Se destacarmos o caso da China, onde a PSA possui, há muito tempo, uma usina em Wuhan já atendida pelos fornecedores de peças locais, os fornecedores selecionados para abastecer as usinas européias do grupo não têm nenhuma experiência de exportação para a Europa, mas deverão imperativamente se inserir na Supply Chain da PSA. De fato, a PSA imporá aos seus fornecedores a entrega na Europa sobre sua própria responsabilidade:

- volumes importantes de peças comuns, que encontramos sistematicamente sobre um dado modelo do veículo, exceto peças correspondendo às opções específicas de um cliente;

- freqüências espaçadas (uma vez por semana) para intensificar os fluxos de contêineres completos;

- MAF (Magasins Avancés Fournisseur - Armazéns Avançados dos Fornecedores) situados na proximidade imediata das usinas européias destinatárias, onde o fornecedor administra os estoques de peças correspondentes a 28 dias de consumo da usina, que serão em seguida entregues na medida das necessidades da fábrica.

A PSA, como cliente destinatária que compra segundo o incoterm $\mathrm{EXW}^{1} \mathrm{MAF}$, impõe aos fornecedores assumir a plena responsabilidade jurídica da cadeia logística de exportação, respeitando rigorosamente suas normas de expedição, de embalagem, de acondicionamento, de etiquetagem, de gestão de estoque, etc.

\section{A estruturação dos fluxos para colocar em prática uma cadeia logística de exportação sobre a responsabilidade jurídica do fornecedor: o caso da PSA}

No exemplo acima citado, os fornecedores chineses administram uma cadeia logística de exportação (65 a 80 dias de prazo) que corresponde a:

- um pré-encaminhamento direto, ou para um centro de consolidação das mercadorias da fábrica de origem para um agente de transporte "intermediário" localizado num porto de embarque chinês, onde são realizadas as operações alfandegárias (4 a 12 dias de prazo);

- um transporte marítimo para um porto europeu (30 dias de prazo);

- operações alfandegárias ou de trânsito na alfândega num porto europeu e a organização pelo agente de transporte transitário do pós-encaminhamento em direção ao MAF ou a uma plataforma (alfandegada ou não) (3 a 10 dias de prazo);

- operações de gestão de estoques e de recondicionamento devido às obrigações particulares das usinas destinatárias e de preparação das entregas (28 dias de estoques).

O cliente PSA, que compra as peças na saída do MAF, assume a responsabilidade do transporte de entrega final (1 a 2 dias de prazo). A PSA considera que desencadeará, via EDI (Intercâmbio Eletrônico de Dados), uma entrega de suas usinas em just in time a partir do MAF. O maior desafio para o fornecedor chinês é planejar, gerir e assumir a estruturação de uma cadeia logística particularmente complexa, que é imposta pelo seu cliente, e isso sem experiência da logística internacional: o recurso a um operador logístico se revela indispensável.

\section{A gestão operacional dos fluxos e o papel do operador de serviços logísticos responsável pela confiabilidade da cadeia logística que entrega às montadoras PSA na Europa}

A inexperiência logística e internacional dos fornecedores oriundos de países emergentes distantes das montadoras clientes, cujos níveis de exigência logística são elevados, só pode ser compensada pela intervenção de um operador cujas competências logísticas e internacionais sejam extensas e reconhecidas. Ora, ainda que a PSA teoricamente não seja responsável pela cadeia logística, qualquer falha nesta trará conseqüências para suas usinas. Desta forma, aos custos dos seus fornecedores, a PSA prepara memoriais descritivos (manuais) que os operadores logísticos dos seus fornecedores deverão seguir, e forçar estes fornecedores a solicitar o mesmo operador logístico para ganho de escala dos fluxos, reduzindo os seus custos.

A GEFCO, subsidiária logística da PSA e que possui larga experiência de abastecimento das montadoras da PSA em todos os lugares do mundo, propõe aos fornecedores de peças da PSA na China uma solução logística integrada das suas usinas chinesas até a gestão de MAF na Europa. A GEFCO, já presente na China, teoricamente estará em concorrência com outros operadores (quase sempre ocidentais...), mas o fato de ser uma filial do cliente a coloca numa situação favorável. Esta oferta compreende:

\section{- Na China:}

- retirada das peças nas usinas de partida em contêineres completos (FCL) ou en contêineres de carga fracionada (LCL);

- paletização das peças, etiquetagem das peças (as normas 
do EDI do setor automobilístico na Europa Galia/Odette), operações alfandegárias;

- expedição de contêineres de peças em direção à Europa;

- acompanhamento das expedições internacionais (tracing \& tracking).

\section{- Na Europa:}

- recepção e controle das mercadorias, transporte das mercadorias para o MAF ou das plataformas situadas na proximidade imediata das usinas PSA;

- estocagem de mercadorias, eventualmente na alfândega, no MAF ou nas plataformas operacionais alfandegárias;

- reembalamento e etiquetagem das mercadorias em embalagens recuperáveis;

- preparação das expedições para as usinas e entregas em função das demandas nas usinas (freqüências multiquotidianas e semanais);

- emissão de documentos EDI.

O operador assume, aos custos do fornecedor chinês e segundo as obrigações impostas pela PSA, o conjunto de operações da cadeia logística China/Europa.

\section{O CASO DO VAREJISTA MUNDIAL}

O varejo é um setor cujas principais empresas (hipermercados: WAL-MART, CARREFOUR, METRO, CASINO etc.; distribuidores especialistas: IKEA, KINGFISCHER, DECATHLON, ZARA, etc.) recorrem cada vez mais aos fornecedores globais, de acordo com a liberalização das trocas impulsionadas pela OMC (Word Trade Organization).

\section{Uma negociação muito difícil com os fornecedores de bens de consumo de massa para construir uma Supply-Chain ampla}

Devido à intensificação da concorrência que os opõe, os distribuidores são confrontados com uma "guerra dos preços" que os pressiona a buscar mais longe os fornecedores com menores custos. Esta tendência, em ruptura com práticas de compras de fornecedores regulares e próximos, perfeitamente identificados, apresenta numerosos riscos:

- a qualidade dos produtos comprados coincide com as amostras e permanecerá suficiente e estável?

- as capacidades de produção são flexíveis e suficientes para poder satisfazer as encomendas em grandes quantidades, mas freqüentemente aleatórias, dos locais de distribuição presentes em vários países (CARREFOUR, o mais globalizado dos hipermercados, está presente em 30 países e tem mais de 12000 pontos-de-venda)?

- os fornecedores de países com baixo custo de mão-deobra, freqüentemente pouco atenciosos às condições de trabalho de seus assalariados e submetidos a uma forte pressão em termos de baixa de preço, respeitarão as normas éticas e ambientais rigorosas impostas pelos distribuidores?

- os fornecedores sabem desenvolver inovações sobre suas ofertas de produtos?

- os prazos negociados são respeitados?

- as entregas efetuadas estão qualitativamente e quantitativamente de acordo com as encomendas?

Muitos distribuidores superam estes problemas detendo incoterm EXW, ou seja, assumem a responsabilidade das mercadorias na saída da usina do fornecedor ou, mais freqüentemente, na saída do armazenamento local onde os fornecedores devem entregar.

\section{A estruturação dos fluxos para colocar em prática uma cadeia logística de exportação sob a responsabilidade jurídica do distribuidor}

Uma das maiores dificuldades encontradas pelos distribuidores nos novos países fornecedores está na inexperiência internacional dos fornecedores e na insuficiência dos recursos logísticos locais disponíveis.

Para superar estas deficiências e para estabilizar a cadeia logística de exportação, os distribuidores assumem o controle. O fato de comprar EXW tem por conseqüência que o distribuidor estrutura a cadeia de exportação selecionando os diferentes interlocutores: transportadores, armazenadores, operadores logísticos, agente de transporte, etc. As mercadorias são entregues pelos fornecedores nos armazéns designados e controlados pelos distribuidores, permitindo verificar nos países de origem a conformidade da qualidade e quantidade das entregas e, portanto, retornar ao fornecedor os produtos fora da conformidade. Posteriormente, os fluxos são centralizados, intensificando, dessa forma, as operações de exportação.

\section{A gestão operacional dos fluxos e o papel da cadeia logística de exportação conectada aos sistemas logísticos do distribuidor nos países de destino}

Os distribuidores impõem a seus fornecedores entregar nos armazéns, onde as mercadorias são inicialmente "normalizadas", para verificar sua conformidade com as restrições operacionais dos sistemas logísticos cada vez mais automatizados dos distribuidores nos países de destino (re-condicionamento, etiquetagem das caixas, etc.). Os distribuidores também procuram se beneficiar do baixo custo de mão-de-obra nos países de origem das mercadorias para realizar dispendiosas operações logísticas outrora efetuadas nos países de destino.

Por exemplo, a preparação das encomendas destinadas a um armazém nos Estados Unidos pode ser efetuada nos 
armazém do país de partida, onde são postas em contêineres que reagrupam todas as mercadorias destinadas a um armazém, dentro dos quais são postas por seções específicas. Tal organização contribui para reduzir os custos de preparação da encomenda, acelerando as operações de entrega do contêiner nos Estados Unidos diretamente ao armazém destinatário, e, conseqüentemente, reduzindo o nível de estoques em trânsito, o que simplifica as operações de reposição final dos produtos.

$\mathrm{Na}$ maioria dos casos, os distribuidores recorrem a operadores logísticos estrangeiros, os quais já tercerizam suas operações logísticas nos seus países de origem. Esta escolha contribui muito para a homogeneidade dos sistemas logísticos nos múltiplos países e facilita a pilotagem da cadeia.

\section{OS TRÊS IMPERATIVOS DO SUCESSO DO GLOBAL SOURCING}

\section{Controlar a relação comercial com o fornecedor}

$\mathrm{O}$ primeiro princípio a ser respeitado para conseguir uma política do global sourcing é controlar perfeitamente a relação comercial com o fornecedor (qualquer que seja o incoterm escolhido) para estruturar a Supply-Chain, cujo desempenho é ameaçado permanentemente pelas numerosas defasagens entre os atores desta cadeia.

$\mathrm{O}$ estudo do grupo Accenture ${ }^{(2)}$ mostra de fato que o nível de satisfação dos grupos industriais face a seus fornecedores "globais" é de $86 \%$ para a redução dos custos, de $58 \%$ para o cumprimento dos prazos, de $52 \%$ para as capacidades de inovação, de $40 \%$ para a qualidade dos produtos e de $33 \%$ para sua confiabilidade. Freqüentemente, o respeito destes imperativos passa pela abertura de escritórios de compras nos países exportadores, em relação permanente com os fornecedores, e pela formação de equipes mistas internacionais associando numerosos funcionários locais.

\section{Controlar o sistema de informação da Supply-Chain}

O segundo princípio a ser respeitado é controlar o Sistema de Informação amplo do conjunto da SupplyChain, para acompanhar e controlar as operações de cada um dos atores e para sobrepor os ocasionais perigos e defeitos. Por esta razão, as empresas locais que não sabem se relacionar via EDI com os parceiros da Supply-Chain são de fato excluídas, qualquer que seja seu desempenho em outros domínios.

\section{Controlar as operações locais e internacionais da Supply-Chain}

O terceiro princípio a ser respeitado pelo cliente é controlar perfeitamente cada operação da Cadeia Logística
Internacional (condicionamento e embalagem, transporte, alfândega, armazenamento, entrega final, etc.), de maneira a reduzir o custo e melhorar a qualidade do serviço. É necessário, de fato, que as economias realizadas ao se recorrer aos países de baixo custo de mão-de-obra não sejam absorvidas, seja pelos sobrecustos logísticos diretamente ligados a distâncias dos fornecedores, seja pelos custos induzidos pelos eventuais gargalos logísticos ligados às fraquezas das infra-estruturas disponíveis nesses países. Para evitar tais riscos, o cliente intervém diretamente no processo de escolha dos fornecedores, exigindo deles o respeito absoluto a um caderno de encargos logísticos, participando da seleção dos operadores logísticos e realizando auditorias regulares junto a cada ator da Supply-Chain.

\section{CONCLUSÃO: QUAL O FUTURO PARA O GLOBAL SOURCING?}

No médio prazo, à medida que os países de baixo custo de mão-de-obra se industrializam e desenvolvem, não existe dúvida de que seus desempenhos para a exportação melhoram (em termos de qualidade e de confiabilidade técnica dos produtos, da confiabilidade da suas cadeias logísticas de exportação e da aplicação das normas impostas pelo respeito às regras ligadas aos princípios de desenvolvimento durável). Este fato os torna mais competitivos para as empresas globais, sempre em busca de uma redução de seus custos.

A longo prazo, o rápido crescimento de alguns desses países poderá ter duas conseqüências suscetíveis de diminuir fortemente sua atração aos olhos das firmas globais na busca de fornecedores de baixo custo e de desestabilizar fortemente as políticas atuais do global sourcing:

- o custo de mão-de-obra progride muito rápido com o crescimento do nível de vida, e os preços de fabricação dos fornecedores locais aos poucos deixam de ser competitivos: este caso já pode se observar nas Ilhas Maurício, cujas indústrias téxteis, que têm largamente se beneficiado das políticas de relocalização da firmas globais, começam a se re-relocalizar em direção a Madagascar...

- o crescimento do consumo interno dos países atualmente exportadores, ligado ao aumento do nível de vida de sua população, poderá empurrar os industriais locais a privilegiar o mercado interno às custas da exportação, com o apoio de seus governos, preocupados em reduzir as desigualdades sociais, nocivas à estabilidade política desses países.

Enfim, as obrigações dos abastecimentos urgentes, ligadas às incertezas crescentes dos mercados, aos poucos 
forçam as empresas, particularmente no varejo, a desdobrar suas redes de fornecedores em: distantes, de baixo custo para as encomendas previsíveis, e próximos, para os reabastecimentos urgentes e aleatórios (respectivamente, $70 \%$ e $30 \%$ dos fluxos para a cadeia de distribuição de vestuário ZARA).

\section{Nota \\ 1. International Commercial Terms: Termo de vendas internacional de- do Comércio para definir as respon- sabilidades dos vendedores e dos \\ EXW: Ex work (a partir do local da compradores o mais claro possível. produção).}

\section{- Referências}

(1) "Délocalisations: aurons nous encore des emplois demain?", P. VILLEMUS, Le Seuil, Paris. 2005

(2) Where East meets West: driving high performance in low-cost country sourcing, Accenture, 2005. Este estudo focaliza um conjunto do setor industrial, do qual fazem parte a indústria automobilística e a dos bens de grande consumação.

(3) Para os conceitos de cadeia logística de Supply-Chain, ver J. COLIN, Le Supply Chain Management existe-t-il réellement? In: Revue Française de Gestion, v. 31 n. 156, 2005. Este artigo foi traduzido em inglês e em português pelo Anuário NTCELogística, n. 2, 2005-2006, Brasília: fevereiro, 2006.
(4) Anuário NTC\&Logística, n. 1, 2004 Brasília.

(5) Pesquisa realizada com a GEFCO em 2006.

\section{- Agradecimentos}

Agradecemos a revisão técnica da tradução deste artigo feita pelo Prof. Fausto Leopoldo Mascia (POLI-USP).

\section{- Sobre o autor}

\section{Jacques Colin}

Diretor do Centre de Recherche sur le Transport et la Logistique (CRET-LOG),

l’Université de la Méditerranée (Aix-Marseille II)

E-mail: colin@univ-aix.fr 